brazilianpoliticalsciencereview

ART I CLE

\title{
The subject of social justice: a defence of the basic
} structure of society*

\author{
Marcos Paulo de Lucca-Silveira \\ Universidade de São Paulo, Brazil
}

In The Idea of Justice (2009), Amartya Sen presents an approach to justice that seeks to make comparisons based on social realizations. This approach focuses attention both on real political-social institutions and on people's behaviour, as well as other potential influences affecting the degree of justice existing in a given society. The new theoretical proposal advanced by Sen (2009) differs then from the theory of justice formulated by John Rawls (1999a) and other contemporary theorists. In the eyes of the Indian author, the theory formulated by Rawls searches for solutions to questions of perfect justice and suffers from problems of feasibility and redundancy. In this article, I argue, centring attention on the question of the appropriate primary subject of social justice, that the critique and subsequent proposal for change of the subject of justice presented by Sen (2009) can be judged mistaken. From a liberal-egalitarian perspective, the primary subject of social justice should be the basic structure of society as formulated by Rawls. Hence I explore the idea that Rawls's option to focus on this subject is directly associated with this particular conception of social justice. I also look to show that Sen's (2009) critique of the redundancy of contemporary theories of justice can be considered implausible. I argue that an ideal theory, such as the one formulated by Rawls, is central to practical guidelines for actions that seek to lessen injustices in real life situations.

Keywords: Basic structure of society; social justice; Rawls; Sen; theories of justice.

(*) http://dx.doi.org/10.1590/1981-38212016000200006

I gratefully acknowledge the grant \#2014/12679-0, São Paulo Research Foundation (FAPESP). I would also like to thank Bruna Gisi, Fabricio Vasselai, João Cortese and especially Álvaro de Vita for the dialogues and suggestions on the ideas developed in the article. My thanks too for the comments and suggestions of the three anonymous reviewers and the editors of BPSR. 
In The Idea of Justice, Amartya Sen (2009) presents an approach to justice that aims to make comparisons based on social realizations, setting the objective of elucidating how we should respond to questions related to improving justice and eliminating injustice. By making considerations of justice and comparisons between states of the world - or, as Sen (2009) puts it, between 'societies' - this approach focuses attention not only on political-social institutions but also on people's behaviour, as well as other potential influences affecting the degree of justice existing in a given society. Furthermore, this conception focused on realizations is concentrated on the behaviours of real individuals and institutions in a given society, rather than supposing possible idealizations (SEN, 2009 , p. 07). Unlike other contemporary theories of justice that attempt to offer solutions to questions concerning the nature of perfect justice, the main subject of Sen's theoretical proposal (2009) is to eliminate evident injustices.

According to the author, there exist three core differences in his line of argument compared to existing theories of justice, particularly the theory developed by John Rawls (1999a). Firstly the approach to justice presented by Sen adopts a procedure of 'plural reasons', with the use of various different lines of argument to condemn situations of injustice, without the need for (the existence of) any agreement about the (single) reason for a dominant diagnosis of injustice. As a result a consensus about injustice can be reached on the basis of various distinct principles, given that "[the] arbitrary reduction of multiple and potentially conflicting principles to one solitary survivor, guillotining all the other evaluative criteria, is not, in fact, a prerequisite for getting useful and robust conclusions on what should be done" (SEN, 2009, p. 04).

Secondly, the theory formulated by Sen (2009) is intended to serve as the grounds for a reasoned argument in the practical domain by including ways of judging (and consequently reducing) existing injustices, thereby promoting justice. Differently to other contemporary theories of justice, this argument aims to enable the evaluation of specific social changes by ranking alternative 'social realizations', each capable of bringing about an incremental improvement in justice within a given society.

Meanwhile the third fundamental difference is Sen's argument (2009) that the presence of a remediable injustice may be connected to a large extent to 
behavioural transgressions rather than institutional defects. Justice would thus be fundamentally linked to how people live and not merely to the nature of the surrounding institutions. In the approach set out by Sen (2009) in The Idea of Justice, therefore, "it is argued that there are some crucial inadequacies in this overpowering concentration on institutions (where behaviour is assumed to be appropriately compliant), rather than on the lives that people are able to lead" (SEN, 2009, p. xi).

As we may already observe, these three differences - which the author himself looks to present and distinguish (see, for example, SEN 2011a, pp. 11-14, 39-57) - are strongly interconnected or even overlap, and generate as their primary outcome the elaboration of a theoretical formulation centred on people's real lives, on the realizations and accomplishments in comparisons of justice. As a consequence, there is a clear shift in terms of the central subject of social justice compared to the theory of justice formulated by Rawls (1999a) - a movement with implications for both the scope and the nature of the idea of social justice. For Sen (2009), the principles of justice need to be focused directly on the lives and freedoms of the people involved, conferring institutions an instrumental role in the pursuit of justice. According to the Indian theorist, when choosing between the justice involved in two situations, institutions should come into the reckoning in relation to the direct contribution made to the lives of people are able to lead, "facilitating our ability to scrutinize the values and priorities that we can consider" (SEN, 2009, p. xii), thereby promoting opportunities for the public debate.

In the present article I propose that, when considered from a liberalegalitarian viewpoint, Sen's proposal (2009) to change the primary subject of social justice appears mistaken. Pursuing a Rawlsian perspective ${ }^{1}$, I argue that the primordial subject of social justice is the basic structure of society and that Sen's (2009)critique of Rawls's (1999a) theory of justice - with special emphasis on the

\footnotetext{
${ }^{1}$ Here I use the term 'Rawlsian perspective' because I present a set of ideas centred on particular aspects of the theory of justice formulated by John Rawls in this article. The arguments that I present here are thus affiliated with a 'Rawlsian theory of justice'. In this article, I do not propose to expound on John Rawls's theory in full. I align my approach with a particular way of exploring normative theory practiced, among others, by Brian Barry (1995) (a specific argument on this question is found in BARRY, 1995, pp. xi-xii). Along with the works of Rawls (1999a, 1999b, 2001, 2005), I make particular use of the theoretical developments presented by Scheffler (2006) and Freeman (2014).
} 
questions of an adequate argumentative approach and the appropriate subject of social justice - is thus erroneous. The argument proceeds in four steps. To begin with (Section I) I sketch some of the central points of Sen's critiques and formulations (2009) as reflected in his decision to reject Rawls's approach (1999a) - in his view, a theory of justice concentrated solely on identifying perfectly just institutional arrangements - and present a distinct line of argument concerning justice, centred on "comparisons of real realizations".

Subsequently, (Section II) I present a particular understanding of the main subject of social justice in John Rawls's theory (1999a), the basic structure of society. I argue that the adoption of this subject of justice is directly associated with a liberal-egalitarian conception of social justice, outlining a particular understanding of the primary subject of social justice in Rawls. In conducting this interpretative exercise, I look to show how Sen's reading (2009) of Rawls's work is in large part superficial.

In Section III, I look to show that the strong critique undertaken by Sen (2009) of the redundancy of theories of perfect justice can be deemed implausible. Finally, in Section IV I briefly highlight some of the points raised earlier and draw a number of final considerations.

\section{Section I}

In presenting his formulation of justice, Sen (2009) aligns his approach with what he delineates as "a variety of comparative approaches that were concerned with social realizations" (SEN, 2009, p. 07). Works by Smith, Condorcet , Bentham, Marx and Mill, as well as contributions from a social choice approach, are identified as pertaining to this lineage. For the Indian author, all these theoretical approaches share the core objective of making wide-ranging comparisons of justice between the different lives that people can lead: these are seen to be influenced by institutions, but also by the real behaviour of these people and by social interactions, among other determining factors.

Sen (2009) also argues that this perspective contrasts with another approach - currently predominant in the contemporary theoretical-normative debate on justice - that concentrates its efforts on identifying perfectly just institutional arrangements for a society (SEN, 2009, p. 05). The central theoretical 
task of the works in this approach is to describe 'just institutions' capable of enabling what is identified as perfect justice. Consequently these lines of argument attempt to identify what is the just and concentrate on shaping the ideal institutions that can provide the basis for this ideal situation of justice, meaning that they do not offer criteria for verifying and comparing justice between nonideal societies. This perspective, which Sen (ano) labels 'transcendental institutionalism', has among its leading proponents philosophers like Hobbes, Locke, Rousseau, Kant and Rawls, as well as other contemporary theorists of justice.

Moreover, according to Sen (2009), this 'transcendental institutionalism' approach can be seen to be strongly connected to the contractualist theoreticalargumentative construction, including the attribution of a central role in these theories to the hypothetical social contract as part of the transcendental identification of ideal institutions. Even the main theoretical contributions of this arrangement-focused analysis - here Sen (2009) foregrounds the works of Kant and Rawls - are taken to possess serious theoretical limitations, derived from idealizations associated with the internal barriers to the arguments typically pursued by the transcendental contractualist perspective: these in turn impede any adequate comprehension of societies and real situations by these theories. As Sen (2009) asserts: "There is, obviously, a radical contrast between an arrangement-focused conception of justice and a realization-focused understanding: the latter must, for example, concentrate on the actual behaviour of people, rather than presuming compliance by all with ideal behaviour" (SEN, 2009, p. 07).

The characteristic transcendentalism of the main contemporary theories of justice contains two fundamental problems that, Sen (2009) argues, hinder a correct investigation of the advances and setbacks to justice evident in real societies. These problems are: (i) the feasibility of encountering an agreed transcendental solution, and (ii) the redundancy of a transcendental solution.

In Sen's view (2009), the question of feasibility is a major problem for contemporary theories of justice - such as the one formulated by John Rawls (see SEN, 2009, pp. 11-12) - which argue for (and present) the possibility of a single agreement concerning (transcendental) justice. What the author is proposing in 
sum is that serious differences may exist between competing principles of justice that survive reasonable critical examination and moreover claim impartiality.

Hence the existence of potentially distinct reasons of justice cannot be discarded, each of them surviving critical examination and, in addition, leading to different conclusions regarding justice. According to Sen (2009), there are a plurality of reasons and impartial normative interests that, even after the use of argumentative reasoning, may not reach any consensus on the existence of a single solution to justice in a given situation. Ultimately, Sen (2009) is proposing that there may be no identifiable principles of justice and social arrangements that comprise perfectly just and unanimous outcomes of an impartial agreement. The solutions of justice, like the two principles of justice presented by Rawls (1999a) ${ }^{2}$, deriving from an agreement between the parties in the original position, may not exist or, when present, may tend to contain some degree of arbitrariness. As the author explains in response to his critics:

In contrast with the insistence in Rawlsian 'justice as fairness', the alternative of a 'social choice' approach (to which my own theory broadly belongs) allow the possibility of a plurality of competing principles - or more exactly a plurality of bundles of combined priorities over acceptable principles - after subjecting them all to critical examination (SEN, 2011b, p. 323).

Sen (2009) thus presents the issue of the feasibility of transcendental theories. Due to the potential plurality of competing principles claiming to be relevant to an evaluation of justice, it is impossible, Sen (2009) argues, to verify the existence of a social arrangement identifiable as perfectly just. Moreover, the plurality of impartial normative interests does not lead to an unanimous choice of an impartial agreement, but in multiple and frequently conflicting patterns of justice (SEN, 2011b, pp. 322-323).

However, beyond this potentially serious issue identified by Sen (2009), contemporary theories of justice - again including Rawls's theory (1999a) possess another flaw, namely redundancy. As the author argues, "[i]f a theory of justice is to guide reasoned choice of policies, strategies or institutions, then the

\footnotetext{
2 Sen (2009) claims that the problem of feasibility also affects the contractualist theory
} formulated by Scanlon (2000). 
identification of fully just social arrangements is neither necessary nor sufficient" (SEN, 2009, p. 15).

In the eyes of the Indian theorist, there is an analytic disconnection between a comparative exercise of non-ideal situations and the identification of arrangements, institutions and other demands belonging to a perfect justice. Albeit not discarding the possibility of motivational connections between these two movements, Sen (2009) seeks to provide a theory of justice that can urgently fill the absence of a comparative evaluation of justice in real states of the world. What Sen (2009) is claiming, in other words, is that theoretical formulations that present arguments about perfect justice, like the theory elaborated by Rawls (1999a), provide little or no help when it comes to taking decisions about questions of justice in contemporary societies. Transcendental theoretical formulations, given the questions that they develop, cannot support responses to situations involving the kind of comparative choices of justice that need to be made on a day-to-day basis in democratic societies.

Consequently, Sen (2009) believes that a radical change is needed in how we formulate a theory of justice, a task that he proposes to undertake. Developing the concept of the impartial spectator - taken from the work of Adam Smith (2010) - Sen (2009) argues that the dialogues on justice need to be analysed through an open and impartial reasoned argument in order to provide plural grounds for evaluating issues of justice and injustice in contemporary societies. This new argument should be constructed within a comparative framework and should focus on the social realizations of the societies involved. That is, it should go beyond the limits of the political-social institutions and observe the comprehensive outcomes of justice in any given society.

Another way of comprehending Sen's theoretical proposal (2009) is to consider it an attempt to shift between two concepts of justice found in the Sanskrit literature on ethics and jurisprudence, niti and nyaya (among other passages, see SEN, 2009, pp. 20-22). While uses of the first concept are related to the adaptation of institutional arrangements and to correct behaviour, nyaya is a comprehensive concept of justice, involving a much broader and more inclusive perspective, concerning not only judgements related to institutions and rules, but also societies themselves. This second concept takes into account how the lives 
that people are able to lead emerge and become realized. While, as Sen (2009) argues, these two distinct concepts of justice must form part of any adequate and complete conception of justice, there is no doubt that the author seeks to emphasize the dimensions associated with the concept of nyaya that, in his view, have been neglected by other contemporary theories of justice. Put succinctly, his proposed theory of justice seeks to go beyond the notion of niti to include a consideration the notion of nyaya too.

It should be stressed, therefore, that, as far as Sen (2009) is concerned, we need to avoid limiting the subject of justice to institutional choices or theoretical formulations developed to identify ideal social arrangements only. Instead, the author advocates an understanding of justice based on social realizations/comprehensive outcomes - one that should present an ample comprehension of social realization, taking into consideration processes and including the exercise of individual rights and responsibilities in its evaluations (SEN, 2011a, p. 54) - and accounting for the lives that people are actually able to lead. As he states:

The importance of human lives, experiences and realizations cannot be supplanted by information about institutions that exist and the rules that operate. Institutions and rules are, of course, very important in influencing what happens, and they are part and parcel of actual world as well, but the realized actuality goes well beyond the organizational picture, and includes the lives that people manage - or do not manage to live (SEN, 2009, p.18).

As we know, Sen's theoretical approach defends the importance of the real capabilities that people can have as an adequate measure of social justice, as well as the defence - at least prima facie - of the huge importance of the freedom to choose from among the different kinds of life that a person could have.

\section{Section II}

Seeking to contribute to the rich debate set off by the publication of Sen's work (2009), I shall present a particular understanding of the primary subject of social justice formulated by Rawls (1999a, 2001, 2005) - the basic structure of society - seeking to show, through an analysis of this concept, how the critical line 
of argument developed by Sen (2009) can be deemed mistaken. I suggest that the primacy of principles of justice for the basic structure of society is connected to the conception of free and equal moral persons and to the necessary conditions for realizing both reciprocity and the fundamental interests of citizens in a democratic society.

In the first sentence of the first chapter of $A$ Theory of Justice, John Rawls (1999a) asserts that "justice is the first virtue of social institutions [...], laws and institutions no matter how efficient and well-arranged must be reformed or abolished if they are unjust. Each person possesses an inviolability founded on justice that even the welfare of society as a whole cannot override" (RAWLS, 1999a, p. 03). A few pages later, the philosopher clearly sets out both the central importance of social justice to his theory and the main subject of this justice: namely, the basic structure of society. As the author declares: "Our topic, however, is that of social justice. For us the primary subject of justice is the basic structure of society, or more exactly, the way in which the major social institutions distribute fundamental rights and duties and determine the division of advantages from social cooperation" (RAWLS, 1999a, p. 06).

Later, in Conference VII of Political Liberalism, John Rawls (2005) refines and develops his understanding of the basic structure as a primary subject of justice. Even more clearly than in A Theory of Justice, in this text Rawls defines the basic structure of society. In his words:

The basic structure is understood as the way in which the major social institutions fit together into one system, and how they assign fundamental rights and duties and shape the division of advantages that arises through social cooperation. Thus the political constitution, the legally recognized forms of property, and the organization of economy, and the nature of the family, all belong to the basic structure of society (RAWLS, 2005, p. 258).

Hence, a contractualist conception of justice assumes the basic structure of society as the primary subject of justice and this "conception of justice that results has a certain regulative primacy with respect to the principles and standards appropriate for the others cases" (RAWLS, 2005, pp. 257-258). The core objective of a theory of justice should thus be the formulation of first principles that offer 
reasonable guidelines for dealing with questions of social justice related to the complex of institutions forming the basic structure of society.

Consequently, Rawls (2005) emphasizes that "[t]here is no attempt to formulate first principles that apply equally to all subjects" (RAWLS, 2005, p. 258): rather, various principles of justice should be developed for the relevant subjects in an appropriate sequence. Unlike the principle of utility, for example, which is taken to apply to all social institutions and human actions, "[t]he first principles of justice as fairness are plainly not suitable for a general theory" (RAWLS, 2005, p. 261). In Rawls's theory, these principles are limited to prescribing that "the basic structure establish certain equal basic liberties for all and make sure that social and economic inequalities work for the greatest benefit of the last advantaged against a background of fair opportunity" (RAWLS, 2005, p. 261).

Diverging then from the supposed universal scope of the principle of utility, the first principles of justice as fairness do not offer reasonable and direct guidelines for many cases and subjects that can be subject to ethical evaluation, such as, for instance, the internal practices of the Churches ${ }^{3}$. Rawls (2011) leaves the reader in no doubt that the two principles of justice do not apply to this case directly, asserting that the most that we can say concerning the associations which include, for example, the Churches - that exist within a basic structure of society is that these must adapt to the requirements that this structure imposes to guarantee background justice (RAWLS, 2011, p. 310).

However, the absence of first general principles cannot be considered a synonym of an unsystematic social contract theory. Rawls (2005) proposes an appropriate sequence of kinds of subjects, with the parties in the social contract

\footnotetext{
${ }^{3}$ I think it is a mistake to associate the theory formulated by Rawls (1999a) with the direct application of the two principles of justice to specific subjects, such as particular institutions, or as a solution to questions of 'local justice' present in part of the Brazilian literature at least. As Vita (2004) correctly argues: "Principles of justice that apply to basic institutional arrangements ('global justice') may not be appropriate for deciding what the right thing to do is in specific decision-making contexts ('local justice'); for example, deciding the criteria for distributing organs for transplants" (Vita, 2004, p. 1150). In other words, general principles of social and political justice may not be adequate (and should not be directly applied) to specific decision-making contexts relating to urgent problems involving acute ethical divergences. These principles of social justice in general constrain (or limit) the principles of local justice, but they are not the same, nor do they determine them in an unequivocal way. This question is briefly examined later in the present article.
} 
proceeding in accordance with this established sequence ${ }^{4}$. As Freeman (2014) reminds us, "there is an 'appropriate sequence' of determination of principles from the point of view of original position, with the principles of social justice determined first" (FREEMAN, 2014, p. 92). Furthermore,

the underlying unity [of contract theory] is provided by the idea that free and equal moral persons are to construct reasonable and helpful guidelines for moral reflection in view of their need for such organizing principles and the role in social life that these principles and their corresponding subjects are presumed to have (RAWLS, 2005, p. 262).

What I think needs to be emphasized, therefore, is that Rawls (1999a, 2005), by affirming that the primary subject of social justice ${ }^{5}$ is the basic structure of society, is making a complex normative choice that involves various subjacent theoretical aspects. It seems to me that neither Sen's critique (2009) of the theoretical approach developed by Rawls, nor a significant portion of the critiques of the subject of Rawlsian justice, take these important sets of theoretical aspects into account. Instead, they mistakenly caricature Rawls's contractualist proposal (1999a) and consequently present a critique (and a subsequent proposal for correcting/altering the subject of social justice) based on this initial error.

As I indicated above, by asserting that the principles of social justice focus on the basic structure of society, Rawls (2005) posits firstly that (i) there is a plurality of first principles of justice that apply to different subjects and institutions, such that the principles of justice for the basic institutions/basic structure possess a 'regulatory primacy' over these other principles. In other words:

\footnotetext{
4 "...with the understanding that the principles of each later agreement are to be subordinate to those of all earlier agreements, or else adjusted to them by certain priority rules" (RAWLS, 2005, p. 262; 2011, p. 310).

${ }^{5}$ In Justice as Fairness, Rawls (2001) makes a change in asserting that "one main feature of justice as fairness is that it takes the basic structure as the primary subject of political justice" (RAWLS, 2001, p. 10, my emphasis). Nonetheless, in the same paragraph the author states that "our focus is almost entirely on the basic structure as the subject of political and social justice"(RAWLS, ibid, my emphasis).
} 
Lesser associations within the basic structure of society have standards of local justice peculiar to their purposes and role, and these are not determined by principles of justice for the basic structure. Nonetheless, these associations must adjust their requirements of local justice to the requirements that the basic structure imposes in order to establish 'background justice' in society as a whole (FREEMAN, 2014, p. 92).

Secondly (ii) within the contractualist structure of argumentation of Rawls's (1999a, 2001) theory, the primacy of the basic structure implies a methodological priority of the principles of domestic justice (that apply to the basic structure of society ${ }^{6}$ ) over the other principles of justice, whether these involve local justice (applying directly to institutions and associations of civil society) or global justice (applying to international law) (RAWLS, 2001, p. 11). Still specifically on the topic of local justice, Rawls (2001) stresses that "[i]n general, principles for the basic structure constrain (or limit), but [do] not determine uniquely, the suitable principles of local justice" (RAWLS, 2001, p. 11).

Thirdly, (iii) the primacy of the basic structure is associated with the distinction made by Rawls (2001) between principles for institutions and principles for individuals, and, moreover, the argumentative precedence of the basic structure is presupposed by this distinction, since (iii.a) the principles of justice as applied to the basic structure of society are necessary for the maintenance of background justice, and, in this form, enable individuals to pursue their objectives without excessive demands on moral behaviour. Furthermore (iii.b) "principles of justice for basic institutions provide content to the institutional rules for individuals that are under a duty to comply with pursuant to their natural duties of justice and obligations of fairness" (FREEMAN, 2014, p. 92).

We cannot assume, then, that the principles of justice appropriate for the basic structure of society are also able to serve to regulate individual conduct in general. As Scheffler (2006) asserts apropos the latter,

[t] he principles of individual conduct must address the full range of moral requirements and permissions that apply to us as individuals. They must clarify the nature of our obligations and natural duties, and

\footnotetext{
${ }^{6}$ In other words, what I refer to in this article as 'social justice'. I decided to leave the terminology 'domestic justice' since this is adopted by Rawls in the previously cited passage from Justice as Fairness (RAWLS, 2001, p. 11).
} 
they must address a wide variety of topics including supererogation, mutual aid, and personal virtues such as benevolence, courage, and mercy (SCHEFFLER, 2006, p. 103).

Moreover, a Rawlsian theory of justice would argue that certain principles for individual conduct are an essential part of a conception of justice since these principles specify how individuals conduct their actions (and themselves) in relation to just institutions. For Rawls (1999a), citizens need to possess a strong and normally effective sense of justice. At the very least, his theory contains a principle of fairness that applies to individuals - one that posits that we are responsible for all our willingly contracted obligations - and a principle that governs the natural duty of justice ${ }^{7}$. Given that the principles of justice relating to the basic structure are primary, they also have an important indirect influence on individual responsibilities and motivations. The principles for individuals are to some extent dependent, therefore, on the principles of the basic structure (due to the appropriate sequence indicated above) and the personal obligations and duties presume an idea of just institutions, with the content of the latter needing to be defined prior to the direct demands placed on individuals (SCHEFFLER, 2006, p. 04).

But what reason would exist for limiting the primary focus of social justice to the basic structure of society? As Rawls (1999a) expounds, there are three main reasons for this approach. The basic structure is the primary subject of justice because (i) its effects are deep and present from the outset; (ii) it influences and gives shape to wishes, desires, aspirations and even the character that individuals come to possess, and, finally, (iii) it assures the maintenance of background justice, the necessary conditions of the just background.

The consequences of the basic structure are profound and present from the outset (RAWLS, 2008, p. 08; 2001, p. 10), since the social conditions in which we develop as individuals - including our relative positions and the means and

\footnotetext{
${ }^{7}$ As Rawls (1999a) elaborates, one of the basic natural duties from the viewpoint of justice as fairness is the duty of justice. This duty "requires us to support and to comply with just institutions that exist and apply to us. It also constrains us to further just arrangements not yet established, at least when this can be done without too much cost to ourselves. Thus if the basic structure of society is just, or as just as it is reasonable to expect in the circumstances, everyone has a natural duty to do his part in the existing scheme" (RAWLS, 1999a, p. 99).
} 
opportunities available to us - determine the range of options and choices that we have in life, as well as shaping our interests, objectives and future prospects. Moreover, the inequities resulting from different starting points are especially deep.

While the observation that 'society' generates effects on individuals is virtually irrefutable, Rawls's astute originality lies in shifting generic responsibility for these influences from a vague concept ('society') to the specific institutions necessary for social cooperation, which comprise the basic structure of society. Furthermore, it is the profound influence that these basic institutions exert on individuals - conceived as free and moral persons with fundamental interests in exercising their moral faculties - that justify the primacy attributed to the basic structure of society (FREEMAN, 2014, p. 95). In Rawls's theory (1999a), people's interests and wishes are partially determined by the basic structure, meaning that they cannot be considered as the ultimate entity justifying choices. As Scheffler (2006) tells us, in the theory of justice as fairness, "[t]he desires and aspirations that individuals happen to have at any given moment enjoy no default moral authority" (SCHEFFLER, 2006, p. 104), as it happens with a pre-existent distribution of properties. In Rawls's words (2005), "the basic structure shapes the way the social system produces and reproduces over time a certain form of culture shared by persons with certain conceptions of their good" (RAWLS, 2005, p. 269).

Consequently there is a close link between the non-consequentialist contractualist approach formulated by Rawls (1999a), his conception of personhood and his conception of society understood in terms of social cooperation and reciprocity. As Freeman (2014) remarks:

Rawls rejects the consequentialist position that fundamental issue in questions of justice is maximizing or otherwise promoting states of affairs. Rawls assumes instead that justice is fundamentally about the nature and moral quality of social relations among persons. The freedom of and equality among persons, and their cooperation on terms of reciprocity and mutual respect are relations and values of paramount importance (FREEMAN, 2014, p.96).

Summarizing, Rawls's theory states that individuals can live freely as equals only in those societies where the institutions of the basic structure respect the two principles of justice in a context of reciprocity and mutual respect. In other 
words, "as opposed to promoting aggregate happiness or some other good state of affairs, it is the moral quality of human relationships and the political/moral values of freedom, equality, reciprocity, and mutual respect that inform the primacy assigned to principles of justice for the basic structure of primary social institutions" (FREEMAN, 2014, p. 96).

The ultimate political-moral value presented by Rawls's (1999a, 2005) constructivist perspective - namely, respect for others as free and equal moral persons who cooperate in relations of reciprocity and mutual respect - cannot be achieved through a 'machine' based on calculations and choices of means and situations that works to optimize or maximize this value. This moral ideal presented by Rawls (1999a) is 'principle-dependent' (FREEMAN, 2014, p. 96): that is, it can only be realized through interpersonal relations between individuals who interact and cooperate in accordance with principles and rules justifiable by procedures that exemplify this value/ideal. Nonetheless, this does not mean that Rawls's (1999a) theory is insensitive to outcomes. If the line of argument that I am presenting is valid, it would be entirely inappropriate to insinuate that Rawls's (1999a) theory can be likened to the maxim pronounced by Ferdinand I: Fiat justitia, et pereat mundus ${ }^{8}$.

As Rainer Forst (2014) aptly points out, the concept of social cooperation performs a central role in the Rawlsian approach, which distinguishes Rawls's (1999a) conception of procedural justice from a conception of libertarian justice9. As the German philosopher avers:

Rawls's conception of 'procedural justice' is geared to social relations and structures such that it leads to a system of social relations and structures such that it leads to a system of social cooperation which express the "sociability of human being" in such a way that they complement each other in productive ways and participate in a context of cooperation which includes all as politically and socially autonomous members (FORST, 2014, p. 32).

8 "Let justice be done, though the world perish". A maxim cited by Sen (2009, p. 21) and associated by the author with a diagnosis of justice comprehended as niti.

${ }^{9}$ Like the conception of justice formulated by Robert Nozick in his work Anarchy, State and Utopia (Nozick, 1974). 
It is precisely because of this particular understanding of justice that in Rawls's (1999a) theory the ideal of free and equal moral persons is achieved only when society and individuals respect the basic rights of everyone and willingly meet the demands set by the basic social institutions, the latter regulated by principles unanimously agreed by these rational and reasonable persons (that is, by the parties that represent it) in the original position. Hence a close connection exists in Rawls's (1999a) work between the ideal of moral person and political society (of Kantian origin) and the basic structure defended as a main subject of justice by the author ${ }^{10}$. The basic structure can be understood as 'the institutional expression' of these latter ideals. As Rawls (2005) asserts, "[t]he freedom and the liberty of moral persons require some public form, and the content of two principles fulfils this expectation" (RAWLS, 2005, p. 281).

The basic structure is also responsible for setting the requirements of background justice. A society only treats its members as equal moral persons when the basic structure satisfies these requirements, providing everyone with a minimum necessary level of moral power - that is, the bases of equality (and equal opportunity) and the social bases of self-respect.

Hence the central question of social justice in Rawlsian theory is directly associated with the question of who the individuals - persons in a society - are (FORST, 2014, p. 33). Differently to Sen (2009) - who in illustrating his argument on justice provides an example of 'allocative justice', that is, centred on the question of how to share out a pre-existing package of goods (or income) based on an independent parameter ${ }^{11}$ - Rawls (1999a) posits that distributive justice aims to respond to problems of choice inherent to the 'social system', or, in other words, questions relating to the definition of basic social institutions. In Rawls's (1999a) theory, then, distribution cannot be considered to be just when the final outcomes

${ }^{10}$ A particular conception of person (and consequently of the social unit) is also directly associated with Rawls's defence (and definition) of the list of primary goods as an adequate measure of distributive justice (RAWLS, 1999b). It seems to me that neither Sen (2009) nor other critics take this connection into account, proposing instead other goods to be distributed without constructing a necessary argument.

11 The case to which I refer is 'Three children and a flute' (SEN, 2009, pp. 15). In this illustrative case we have to decide which of three children with different claims and preferences (defended by distinct independent principles of justice) should keep the flute that they are fighting over. 
respect or maximize a predetermined conception of allocation ${ }^{12}$. On the contrary, a distribution is just when it results from a process in which individuals are freely involved in economic activities within a context where the requirements of background justice are realized/respected and where they themselves comply with the same. Differently to the proposal based on 'social realizations' presented by Sen (2009) ${ }^{13}$, we need to understand the idea of distributive justice in Rawls (1999a) as pure procedural justice ${ }^{14}$.

Precisely because of this particular comprehension of distributive justice, the focus on the basic structure of society is also a necessary element in maintaining background justice. One of the fundamental roles of (economic and legal) institutions is to establish and sustain background justice, providing certain necessary equitable conditions for the actions of individuals and associations. As Rawls (2005) asserts:

12 Regarding specifically the illustrative case (of the three children and a flute), the proposal presented by Sen (2009) can be considered one of allocative justice since in this case the central question to which the author looks to respond - or show the impossibility of a single response - is "who should keep the flute". We have an existing good (a flute) and three individuals (the children) claiming an interest in possessing this good on the basis of independent principles of justice (such as knowing how to play it, being the poorest, or having made the flute). We could, then, associate this question presented in Sen's example with the formulations of allocative justice, which seek to respond to the question of what people should receive in accordance with an independent parameter of justice (see FORST, 2014, p. 33). Distinct from a Rawlsian conception of procedural justice, centred on the question of who individuals are, conceptions of allocative justice set out from the premise of the existence of scarce goods that should be distributed to people in a just way - based on independent parameters of justice - without ultimately questioning the mainstays of distributive justice, such as the institutions of a society in general, the structures of production and distribution, and social organisation.

${ }^{13}$ Sen (2009), defending his proposal of 'comprehensive outcomes', avoids considering it a consequentialist philosophical theory, emphasizing the strong critiques directed at these theories in the contemporary literature. However, as the author himself stresses, there is a particular 'consequential reasoning' in his proposal of 'comprehensive outcomes'. This 'consequential reasoning' appears in the ideas of responsibility and responsible choice that his theory incorporates and advocates (SEN, 2009, pp. 217-219). In his words: "It is, however, important to see that consequence-sensitive reasoning is necessary for an adequately broad understanding of the idea of responsibility. This has to be a part of the discipline of responsible choice, based on the chooser's evaluation of states of affairs, including consideration of all the relevant consequences viewed in the light of the choices made and the comprehensive outcomes associated with what happens as a result" (SEN, 2009, p. 218).

14 "Therefore, if it is asked in the abstract whether one distribution of a given stock of things to definite individuals with known desires and preferences is more just than another, then there is simply no answer to the question" (RAWLS, 2005, p. 282). 
Unless this structure is appropriately regulated and adjusted, an initial just social process will eventually cease to be just, however free and fair particular transactions may look when viewed by themselves. [...] Again, the conditions necessary for background justice can be undermined, even though nobody acts unfairly or is aware of how the overall result of many separate exchanges affects the opportunities of others (RAWLS, 2005, p. 266).

It follows that certain rules applicable to economic agents in their everyday transactions (as a means to avoid subsequent undesirable distributions) would, in Rawls's view (2011), be excessive, if not simply impossible. Hence we need special institutions to preserve background justice, accompanied by a special conception of justice that defines how these institutions are to be structured (RAWLS, 2011, p. 317).

As the author reminds us, "the rules governing agreements and individual transactions cannot be to complex, or require too much information to be correct applied" (RAWLS, 2005, p. 267), bearing in mind the high costs imposed on any transaction. Hence, as stated earlier, Rawls (2005) proposes a division of work between rules pertaining to the basic structure and the rules and norms that apply directly to individuals and associations (RAWLS, 2005, p. 268; SCHEFFLER, 2006, pp. 107-108). In the eyes of the philosopher, "any contract theory must recognize that a division of labour is necessary between the operations of the basic structure in maintaining background justice and the definition and enforcement by the legal system of the rules that apply directly to individuals and associations, and govern their particular transactions" (RAWLS, 2005, p. 288).

In contrast to an erroneous reading that considers Rawls's (1999a, 2005) theory to exempt individuals entirely from onerous responsibilities for assuring social justice, this moral division of work corresponds to a form of pluralism concerning moral values and principles. Rawls's (1999a, 2005) theory presupposes the latter in accepting the diversity of incommensurable and tolerable conceptions of good and (comprehensive and reasonable) moral and religious doctrines that potentially exist in a liberal democratic society. As Scheffler (2006) explains: " The idea is not that there no moral principles that regulates individual conduct, so that field is clear for the unrestricted pursuit of self-interest, but rather that the principles for the basic structure do not supersede the complex and varied principles and values that apply to individuals" (SCHEFFLER, 2006, p. 107). 
The point to be emphasized, then, is that the principles of justice in Rawls's (1999a) theory are not conceived as direct or general guidelines for individual conduct, which does not exempt individuals from responsibilities of justice.

\section{Section III}

As argued previously, Sen (2009) claims that theories of perfect justice are completely redundant, offering no practical guideline to actions designed to lessen the injustices present in the contemporary world. The search for unique responses - based on a standard of theoretical consistency and completeness - are taken to push contemporary theories of justice towards an excessive idealization and thus redundancy.

First of all, it should be emphasized that Sen's (2009) distinction between (theories of) 'transcendental' justice and a comparative approach is somewhat obscure. As Satz (2012) emphasizes, the supposed duality between these modes of elaborating theory is exaggerated by the philosopher. Likewise, the conceptual distinction between the transcendental and comparative approaches is neither self-evident or presented clearly by Sen (2009). While a close association between transcendental justice and ideal theory, or between a comparative approach and non-ideal theory, may shed light on certain points, it may also be deceptive. Doesn't the comparative approach formulated by Sen (2009) involve making a number of abstractions that distinguish it from strictly non-ideal perspectives?

Neither does the way in which Sen (2009) develops his critique of the redundancy of transcendental theory facilitate a precise understanding of their conceptual differentiations. The analogy with art is problematic. According to Sen (2009), when we have to choose between a work by Picasso and a work by Dali, the information that the ideal work of art is the Mona Lisa provides no help to us. But, as Kamm (2011) elaborates, a comparison between art and justice would be misguided:

There are no general rules or principles by which to create or to judge a work of art such that we can be sure that an artwork that does not abide by these rules or principles is less good than one that does. If there are 
no general principles, there is no temptation to think that knowing what the best work of art is would allow us to discover principles by which to judge other works of art. [...] By contrast, it is possible that by considering an ideally just state of affairs, we might find general principles for perfect justice (KAMM, 2011, pp. 84-85).

Furthermore, responses to complex questions of justice - such as the questions of gender inequality and iniquities in healthcare - may only be possible through a high level of abstraction in which the identification of an optimal point (of perfect justice) is central. Many conflicts and dilemmas concerning questions of justice can only be plausibly confronted when we consider this ideal ${ }^{15}$.

It is true, though, that the importance of an ideal theory - one that establishes one (or more) optimal point - is an open question in the contemporary literature. While Amartya Sen (2009) proposes that a good theory of justice must be 'action-guiding', political theorists like G. A. Cohen (2003), on the other hand, argue that the theoretical inquiry into political and moral questions is valuable per se, in a way largely independent from its practical (and especially immediate) importance (COHEN, 2003).

In contrast to Sen's (2009) critical diagnosis, though, the idea of a perfectly just society functions as a regulatory and thus non-redundant ideal. Moreover, as Satz (2012) stresses, "the drive for a 'perfect' theory actually arises from within our everyday comparative and evaluative thinking about what we should do in the context of complicated cases" (SATZ, 2012, p. 284). Given this fact, it can be presumed that "the line between comparative assessment and ideal theorizing is less sharp [...] than Sen takes it to be" (SATZ, 2012, p. 284).

As Satz (2012) argues, an ideal theory also provides us with a point towards which we can aim and by which we can evaluate our progress, thereby performing a valuable role in the process of reflecting on existing injustices (SATZ, 2012, p. 285). Additionally, the decisions stemming from a comparative (non-ideal) approach may, in my view, betray a temporal inconsistency - something that occurs when the option for the best policy in $t_{0}$ for a future time $t_{1}$ is no longer the best policy when $t_{1}$ is reached - whether this is caused by a hyperbolic discounting,

\footnotetext{
${ }^{15}$ In this article I adopt a particular theoretical position, in defence of ideal theories of justice, on which no consensus exists in the contemporary literature. A contrary position is presented, for instance, by Young (1990).
} 
an unforeseen strategic interaction, or path-dependency ${ }^{16}$. In other words, without an optimal point on the basis of which we can evaluate our actions and choices, we end up drifting along with circumstances, ultimately unable to know whether our actions work diachronically to reduce mundane injustices. Finally, an approach limited to ranking available alternatives through a comparative method is at risk of overlooking unpresented possible choices.

It seems to me that a strictly comparative approach would confront problems only solvable through the help of ideal theories, including the theory of justice as fairness presented by Rawls (1999a, 2001). Consequently, I conclude that contemporary theories of justice dedicated to presenting ideal considerations of justice are not redundant as Sen (2009) insists.

Even accepting that the main purpose of a theory of justice is to function as a guide to action, the accusation that a theory like Rawls's fails to provide such a guide proves unfounded. As Valentini (2011) states: "the claim that a society is (or can be) perfectly just says something important about both the nature of the value of justice, and how to orient our actions in the real world" (VALENTINI, 2011, p. 305). Fully accepting Sen's (2009)critique exposes us to the risk of considerably underestimating the diverse roles performed by an ideal theory. As I sought to demonstrate in the previous section, there is a clear difference between a utilitarian and/or consequentionalist theory of justice - in which the just is reduced to maximizing a good or something like a utility - and a Rawlsian theory of justice. When it comes to providing an exposition and justification for these foundational and structural differences in conceptions of justice, ideal theoretical formulations perform an important function. Ideal theories also play important roles in situations in which there is no agreement even on the scarce goods that should be distributed, or on the criteria to be used in their distribution ${ }^{17}$. In my view, in situations involving such extreme disagreement - frequent enough in the contemporary political arenas - it is precisely the strictly comparative theories

\footnotetext{
${ }^{16}$ As Elster (2000) suggests, "the preference reversal involved in time-inconsistency is not caused by exogenous and unforeseen changes in the environment, nor by a subjective change in the agent over and above the reversal itself. The reversal is caused by the mere passage of time" (ELSTER, 2000, p. 24). Other points deserving a more detailed analysis from the approach advocated by Sen (2009) are the questions of subjective changes of preferences and adaptive preferences.

${ }^{17}$ For a similar angle on this question, see Valentini (2011), especially section 4.2.
} 
that have little to tell us or help us, given that any comparison between situations (or concerning which good should be taken into consideration in such a comparison) may be made inviable by a prior political disagreement, for instance, on the importance (or not) of a political or moral value.

\section{Section IV}

If the considerations expounded in the previous sections are correct, it can be concluded, I believe, that most of the criticisms directed by Sen (2009) at Rawls's (1999a)formulation of a theory of justice can be deemed mistaken. A conceptual understanding of the basic structure of society as the main subject of social justice enables us, albeit indirectly, to identify the superficial and indeed fictitious nature of the theoretical target created by Sen's (2009) critique ${ }^{18}$.

In contrast to some readings that look to reconcile the theoretical position outlined by Sen (2009) with the theory of justice as fairness, as formulated by John Rawls (1999a, 2001), I think that accepting Sen's (2009) critical argument, which I partly sought to outline in section I, would entail a major rupture between the theoretical position found in The Idea of Justice and the normative positions of Rawlsian origin. Despite the explicit recognition made by Sen (see 2011b) of the importance of Rawls's thesis (1999a), its influence on his own work and the proximities between his own theory and central elements of the theory of justice as fairness, I believe that the theoretical dissonances are actually decisive ${ }^{19}$. While it is true that until the publication of The Idea of Justice there were more convergences than divergences between a Rawlsian perspective of social justice that is, a distributive justice approach centred on assuring equality of opportunity - and a perspective that aims to protect human capabilities, Sen's (2009) work manifests a clear distance in theoretical position vis-à-vis the Rawlsian perspective ${ }^{20}$.

18 Laura Valentini (2011), pursuing a different line of argument, also reaches a similar conclusion on Sen's criticisms (2009) of Rawls's theory (1999a). In her words: "Most of Sen's criticisms are in fact either based on a misrepresentation of the Rawlsian approach, or correct but of little consequence" (VALENTINI, 2011, p. 298).

${ }^{19}$ On the presentation of these proximities, see, for example, Sen (2011b, p. 320).

20 On the convergences between these two perspectives - especially when we focus on health issues - see Daniels (2010). 
As I suggested above, Sen (2009) rejects as a whole the contractualist (and constructivist) perspective of justice presented by Rawls(1999a), in which it would be possible, through a fair and impartial process, to select principles of justice applicable to the basic structure of society. In my view, this complete epistemic rejection of the way in which Rawls's (1999a) theory is constructed has the inevitable consequence of discarding the enormous normative contributions offered by Rawls's (1999a) theory of justice. However, this radical step - which in my view would be inevitable were we to take Sen's (2009) critique seriously - is one that the author himself (Sen, 2011b) refrains from taking.

Nonetheless, what I think needs to be emphasized is that, if correct, Sen's (2009) critique of the proposal formulated by Rawls (1999a) is extremely potent and comprehensive. Accepting the validity of this critical dimension, the positive part of Sen's (2009) line of argument, present in The Idea of Justice, would emerge as a highly original conception of justice in many ways rivalling the idea of justice as fairness.

However, if we consider Sen's (2009) critique incorrect or largely exaggerated and/or directed at a theoretical caricature, we can concluded that much of the proposed formulation of justice present in The Idea of Justice diverges little from the theoretical contribution made by Rawls (1999a) ${ }^{21}$.

This, I believe, is the point requiring emphasis. Consequently I propose to foreground a latent meta-theoretical question that remains implicit to much of the theoretical debate on Sen's (2009) most recent argument on justice. In my view it is theoretically incompatible to (1) accept significant parts of the theoretical construction of Sen's (2009) critique of Rawls's theory (1999a) and, at the same time, (2) seek to reconcile points and conclusions of justice as fairness, with a theoretical-comparative perspective centred on social realizations. An 'ecumenical' theoretical proposal must necessarily reject a substantial part of the argumentative construction informing Amartya Sen's (2009) critique of contemporary theories of justice, especially the theory of justice presented by Rawls. However, this rejection of important points of the critical dimension of

21 Albeit with less theoretical impetus and more obscure points. I admit to serious problems in reconciling the proposals. The final argument developed here is already present in less explicit form in Freeman (2012). 
these 'transcendental institutionalist' theories would, in my view, significantly reduce the importance of the theoretical contribution present in the book The Idea of Justice.

On the other hand, and at the risk of repeating myself, I stress that if we accept the critical part of Sen's (2009) theoretical formulation, we are compelled to abandon entirely - something that Sen (see 2011b) himself avoids - a 'transcendental' theory of justice of the kind developed by Rawls (1999a) when we seek to make comparisons of justice. If the solutions and principles of justice presented by Rawls (1999a) are legitimate and normatively correct in the eyes of the advocates of 'comparative theories', it is up to them to present a new way of constructing and defending these normative positions independently from the argument expounded by Rawls (1999a).

In rejecting a contractualist conception of justice as fairness, we are also obliged to reject one of its essential characteristics, namely the tenet that the basic structure of society is the primary subject of social justice, as well as its main outcomes and normative recommendation. In my view, this rejection appears unfounded.

Translated by David Rodgers

Submitted in October 2014

Accepted in December 2015

\section{References}

BARRY, B. (1995), Justice as impartiality. A treatise on social justice. Vol. 02. Oxford: Oxford University Press. 336 pp.

COHEN, G. A. (2003), Facts and principles. Philosophy and Public Affairs. Vol. 31, Issue 03, pp. 211-245.

DANIELS, N. (2010), Capabilities, opportunity, and health. In: Measuring Justice: primary goods and capabilities. Edited by BRIGHOUSE, H. and ROBEYNS, I.. Cambridge: Cambridge University Press. pp.131-149.

ELSTER, J. (2000), Ulysses unbound: studies in rationality, precommitment, and constraints. Cambridge: Cambridge University Press. 301 pp.

FORST, R. (2014), Justification and critique. Towards a critical theory of politics. Cambridge: Polity Press. 240 pp. 
FREEMAN, S. (2012), Ideal theory and the justice of institutions vs. comprehensive outcomes. Rutgers Law Journal. Vol. 43, Issue 2, pp. 169-209.

FREEMAN, S. (2014), The basic structure of society as the primary subject of justice. In: A companion to Rawls. Edited by MANDLE, Jon and REIDY, David A.. West Sussex: Wiley Blackwell. pp. 88-111.

KAMM, F. (2011), Sen on justice and rights: a review essay. Philosophy \& Public Affairs. Vol. 39, № 01, pp. 82-104.

NOZICK, R. (1974), Anarchy, state and utopia. New York: Basic Books. 334pp.

RAWLS, J. (1999a), A theory of justice. Revised Edition. Massachusetts: Belknap Press of Harvard University Press. 560 pp.

RAWLS, J. (1999b), Collected Papers. Massachusetts: Harvard Univ. Press. 672 pp.

RAWLS, J. (2001), Justice as Fairness: a restatement. Massachusetts: Belknap Press. $240 \mathrm{pp}$.

RAWLS, J. (2005), Political liberalism. Expanded Edition. New York: Columbia University Press. 525 pp.

RAWLS, J. (2008), Uma teoria da justiça. 3a Edição. São Paulo: Martins Fontes. 765 pp.

RAWLS, J. (2011), O Liberalismo político. Edição Ampliada. Translation: Álvaro de Vita. São Paulo: Editora WMF Martins Fontes. 712 pp.

SATZ, D. (2012), Amartya Sen's: The idea of justice: what approach, which capabilities? Rutgers Law Journal. Vol. 43, Issue 02, pp. 277-293.

SCANLON, T. (2000), What we owe to each other. Massachusetts: Belknap Press. $432 \mathrm{pp}$.

SCHEFFLER, S. (2006), Is the basic structure basic? In: The egalitarian conscience. Edited by SYPNOWICH, C.. New York: Oxford University Press. pp. 102-129.

SEN, A. (2009), The idea of justice. Massachusetts: Belknap Press of Harvard University Press. 496 pp.

SEN, A. (2011a), A ideia de justiça. São Paulo: Companhia das Letras. 487 pp.

SEN, A. (2011b), Reply. Rutgers Law Journal. Vol. 43, Issue 02, pp. 317-335.

SMITH, A. (2010), The theory of moral sentiments. London: Penguin Classics. 544 pp. 
VALENTINI, L. (2011), A paradigm shift in theorizing about justice? A critique of Sen. Economics and Philosophy. Vol. 27, pp. 297-315.

VITA, A. (2004), A necessária frugalidade na aplicação de princípios de justiça. Acessed on http://bases.bireme.br/cgibin/wxislind.exe/iah/online/?IsisScript=iah/iah.xis\&src=google\&base=LILAC S\&lang=p\&nextAction=lnk\&exprSearch=385189\&indexSearch=ID ).

YOUNG, Iris Marion (1990), Justice and the politics of difference. Princeton: Princeton University Press. 304 pp. 